\title{
ANALYSIS OF DEFLECTION AND CRACKING OF CONCRETE BEAMS WITH NON-METALLIC REINFORCEMENT
}

doi: $\quad 10.2478 /$ czoto-2019-0100

Date of submission of the article to the Editor: $08 / 11 / 2018$

Date of acceptance of the article by the Editor: 28/12/2018

\author{
Marta Kosior-Kazberuk ${ }^{1}$ - orcid id: 0000-0001-8171-2242 \\ Julita Krassowska ${ }^{1}$ - orcid id: 0000-0001-9209-1285 \\ 1Bialystok University of Technology, Poland, j.krassowska@pb.edu.pl
}

\begin{abstract}
The composite bars have become a useful substitute for conventional reinforcement in civil engineering structures for which load capacity and resistance to influences of environmental factors' are required. Considering the requirements of responsible design of engineering structures with particular emphasis on durability, the use of non-metallic reinforcement in reinforced structural elements allows to reduce the costs related to erection of buildings, as well as the costs of building maintenance and renovations. The behaviour of model beams made of concrete reinforced with composite bars (fiber reinforced polymer bars) in three-point bending test was analyzed. The strength parameters of composite bars were tested. The bending capacity, deformation of concrete, and beam deflection were determined. Crack propagation in the model beams under load was analyzed using the Aramis $5 \mathrm{M}$ optical measuring system. Due to the strength characteristics of the composite reinforcing bars, the beams exhibited significant tensile strains, which resulted in the development of cracks of considerable width.
\end{abstract}

Keywords: BFRP bars, basalt fibers, fiber reinforced concrete, deflection, cracks

\section{INTRODUCTION}

The steel bars are typical reinforcement of concrete structures. Unfortunately, steel reinforcement is characterized by low resistance to corrosion, which causes a significant threat to the durability of reinforced concrete structures. There is therefore a need to look for an alternative reinforcement, with improved properties and resistant to corrosion.

Considering the needs of the building industry and the development of material engineering, a new type of reinforcement Fiber Reinforced Polymer (FRP) was created. The FRP bars are made of continuous fibers and epoxy or polyester resins using the pultrusion method. This technology is based on dragging the material through a set of nozzles forming the fiber strands, which are later immersed in the resin and formed into smooth bars, and then wrapped with roving acting as ribbing, analogously to conventional steel reinforcing bars (ACl 440.1R, 2006; KosiorKazberuk and Wasilczyk, 2017). 
When choosing the type of fibers for non-metallic bars which task is to transfer loads in the structure, one should consider the value of the Young's modulus, which should be greater than the modulus of elasticity of concrete. When selecting fibers for bars, the specific density plays an important role, because the smaller it is, the lighter the reinforcement, as well as the whole structural member, will be. For example, basalt fiber reinforced polymer (BFRP) bars are four times lighter than steel ones (Fiore et al., 2015). Another important parameter is the tensile strength. BFRP bars are characterized by tensile strength even three times higher than steel reinforcement (Lapko and Urbański, 2015). Due to its structure (preserved basalt properties), basalt fibers are also characterized by thermal insulation and low moisture absorption (Branston et al., 2016). A very big advantage of BFRP reinforcement is the possibility of using it at high temperatures, up to $1650^{\circ} \mathrm{C}$. Working temperature is extremely important especially in a fire situation (Borhan 2012; Zhu et al., 2014). Basalt fibers are 100\% corrosion resistant (Zhang and Shan, 2014).

BFRP reinforcement is an anisotropic material, which means that in the longitudinal direction the physical and mechanical properties depend on the properties of fibers, and in the transverse direction its properties depend on the characteristics of resin. The research works of BFRP bars, which confirmed their applicability in reinforced structures, were conducted, among others, by Elgabbas et al. (2016), Lapko and Urbański (2015), Atutis et al. (2018), Duic et al. (2018). However, the studies conducted by Lapko and Urbański (2015), Elgabbas et al. (2016) showed that BFRP reinforced beams with a low reinforcement degree were characterized by high values of strains in the compression zone and several times larger strains in the tensile zone than analogous members with steel reinforcement $(R C)$. Similar observations concerned the deflections of BFRP beams compared to RC beams. Due to the corrosion resistance, the use of FRP bars allows to reduce the thickness of the concrete cover of reinforcement, which also allows to reduce the dimensions of the structure cross-sections (Branston et al., 2016; Elgabbas et al., 2015). Atutis et al. (2018) examined the concrete members with prestressed BFRP bars. The results confirmed the possibility of increasing stiffness of beams subjected to bending. The BFRP stirrups effectively delayed shear damage in the case of low reinforcement amount (less than 1.0\%) and they effectively increased stiffness in the initial phase after cracking (Duic, 2018).

Dissemination of non-metallic reinforcement requires further research and development of structural design guidelines. The aim of the research presented in the paper was to assess the effectiveness of using alternative BFRP reinforcement in concrete beams.

\section{METHODOLOGY}

The tests were carried out on beams with non-metallic reinforcement (basalt fiber reinforced polymer) made of concrete with dispersed reinforcement in the form of basalt fibers incorporated in the amount of $8 \mathrm{~kg} / \mathrm{m}^{3}$. To compare the results the beams with steel reinforcement made of concrete without fibers were also tested.

The cement CEM I 42.5R content in concrete was $320 \mathrm{~kg} / \mathrm{m}^{3}$ and $w / c$ ratio was 0,50 . A mixture of sand and gravel with grain diameter up to $16 \mathrm{~mm}$ was used as aggregate. The fibers were introduced as a replacement of the adequate portion of aggregate by volume. Table 1 gives the mix proportions for reference concrete. The modified polycarboxylate and phosphonate based super-plasticizer (1\% related to 
cement mass) was used to minimize fiber clumping and enhance fiber dispersion in concrete.

Table 1. Mix proportions of the reference concrete.

\begin{tabular}{|c|c|c|c|c|c|}
\hline$w / c$ & $\begin{array}{c}\text { Cement } \\
{\left[\mathbf{k g} / \mathbf{m}^{3}\right]}\end{array}$ & $\begin{array}{c}\text { Water } \\
{\left[\mathrm{kg} / \mathbf{m}^{3}\right]}\end{array}$ & $\begin{array}{c}\text { Sand } \\
{\left[\mathrm{kg} / \mathbf{m}^{3}\right]}\end{array}$ & $\begin{array}{c}\text { Gravel } \\
\mathbf{2 - 1 6} \mathbf{~ m m} \\
{\left[\mathbf{k g} / \mathbf{m}^{3}\right]}\end{array}$ & $\begin{array}{c}\text { Superplasticizer } \\
{\left[\mathrm{kg} / \mathbf{m}^{3}\right]}\end{array}$ \\
\hline 0,5 & 320 & 160 & 732 & 1203 & 3,2 \\
\hline
\end{tabular}

As a dispersed reinforcement, basalt fibers with a length of $50 \mathrm{~mm}$ and a diameter of $20 \mu \mathrm{m}$ were used. The tensile strength of basalt fibers was equal to $750 \mathrm{MPa}$ and Young modulus was equal to $90 \mathrm{GPa}$. Basalt fibers were characterized by bulk density of $1900 \mathrm{~kg} / \mathrm{m}^{3}$.

BFRP bars were characterized by guaranteed tensile strength $f_{f u}^{*}=1180,0 \mathrm{MPa}$, design modulus of elasticity $E_{f}=47,6 \mathrm{GPa}$ and guaranteed rupture strain of FRP reinforcement $\varepsilon_{f u}^{*}=2,0 \%$, determined according to the standard $\mathrm{ACI} 440.1 \mathrm{R}$ (2006).

The strength properties of concretes with fibers and reference concretes such as compressive strength $f_{c m}$, flexural strength $f_{c t m}$ and Young modulus $E_{c m}$ were determined.

In the experimental programme, the tests of two series of single-span beams were assumed, differing in the type of longitudinal and transverse reinforcement. Each series consisted of 2 beams with dimensions $120 \times 300 \times 4500 \mathrm{~mm}$.

The beams were reinforced with stirrups spaced according to PN-EN 1992-1-1 due to the maximum acceptable spacing of stirrups. Beam support points were placed at a distance of $0.15 \mathrm{~m}$ from the outer edge of the beams, resulting in a span in the axes equal to $l_{\text {eff }}=4,200 \mathrm{~mm}$. The shear span-depth ratio $a_{v} / d$ was equal to 4,5 . In the A series, the main longitudinal reinforcement was composed of steel bars. In the compression zone, $2 \varnothing 12 \mathrm{~mm}$ was used, and in the tensile zone $-4 \varnothing 16 \mathrm{~mm}$. Structural stirrups and clamps were made of $\varnothing 6 \mathrm{~mm}$ steel bars. In the B series, the main longitudinal reinforcement was composed of BFRP bars. In the compression zone, $2 \emptyset 12 \mathrm{~mm}$ bars were used, and in the tensile zone $-4 \emptyset 14 \mathrm{~mm}$. Structural stirrups and clamps were made of basalt bars $\varnothing 6 \mathrm{~mm}$.

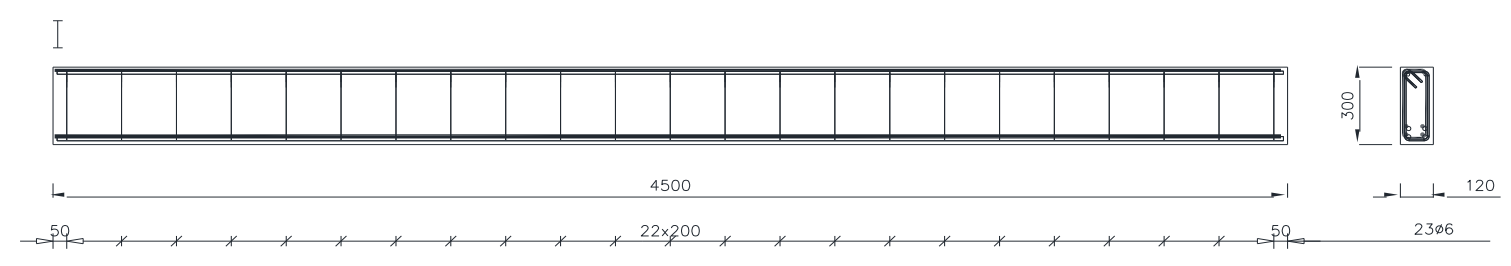

Fig. 1. Schema of reinforcement in beams tested

The beams were loaded in a four-point system using a load increase every $5 \mathrm{kN}$, until tle element was destroyed. Schema of load of beams with the system of measure points' location was presented in Fig. 2. The measure points were indicated with $U$ $1 / 2 / 3 / 4$. During the tests, the shear capacity and/or bending capacity of the beams were determined. a Digital Image Correlation (DIC) technique using a digital recording camera "Aramis" by GOM was applied to monitor the development of the cracks and measure their widths, and to detect strain components. 


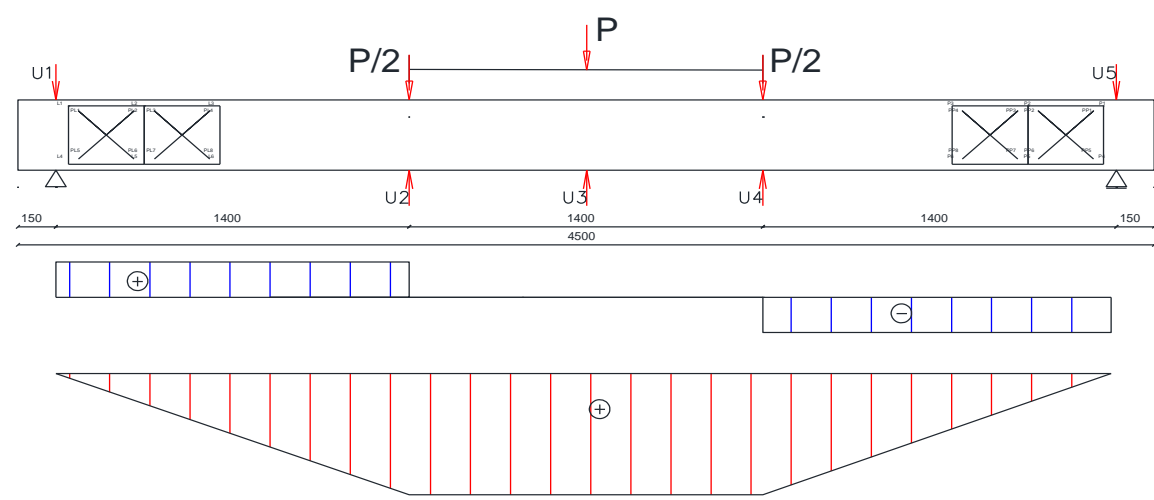

Fig. 2. Schema of load of beams with the system of measure points' location

\section{RESULTS}

\subsection{Properties of concretes}

Table 2 presents the results of strength properties tests: compressive strength $f_{c m}$, flexural strength $f_{c t m}$ and modulus of elasticity $E_{c m}$ (average values and standard deviation).

Table 2

Strength parameters of concretes tested

\begin{tabular}{|l|l|l|l|}
\hline \multirow{2}{*}{ Fiber content } & $\boldsymbol{f}_{c m}$ & $\boldsymbol{f}_{c m t}$ & $\boldsymbol{E}_{c m}$ \\
\cline { 2 - 4 } & {$[\mathrm{MPa}]$} & {$[\mathrm{MPa}]$} & {$[\mathrm{GPa}]$} \\
\hline No fiber $(\mathrm{W} 0)$ & $65,17 \pm 6,70$ & $4,14 \pm 0,49$ & $45866,94 \pm 1,20$ \\
\hline $8 \mathrm{~kg} / \mathrm{m}^{3}(\mathrm{WB})$ & $72,50 \pm 1,79$ & $5,55 \pm 0,28$ & $44150.44 \pm 0,56$ \\
\hline
\end{tabular}

The incorporation of basalt fibers into concrete did not significantly affect the compressive strength $f_{c m}$ and the modulus of elasticity $E_{c m}$. The increase in flexural strength of concrete was $35 \%$. The concrete specimens with basalt fibers were destroyed due to fracture as a typical concrete without fibers, however, the destructive force of the specimen was much higher.

\subsection{Analysis of failure mode of RC beams and BFRP beams}

Figs 3 and 4 show a failure model of RC beams and beams with composite reinforcement along with cracking pattern of beams.

The behavior of beams in the initial phase was similar for both types of reinforcement. After achieving the cracking load in the middle part of the element, cracks were created perpendicularly to the longitudinal axis of beam, as a result of the bending moment. In the case of BFRP beams, the value of cracking moment was $28 \%$ lower in comparison to RC beams. With further increase in load, the perpendicular cracks increased in the middle zone of the beam, expanding the range of the cracked zone towards the support (diagonal cracks were created). Both RC and BFRP beams were destroyed due to bending in the cross-section, where the load was applied. BFRP beams were subject to sudden destruction as a result of brittle cracking of basalt reinforcement, as shown in Fig. 5. Steel bars deformed elastically until they reached the elastic limit. However, the BFRP bars deformed elastically until they failured. A clearly smaller number of cracks in a beam reinforced with steel bars was caused by a limited deformation of these beams compared to beams with non-metallic reinforcement. 

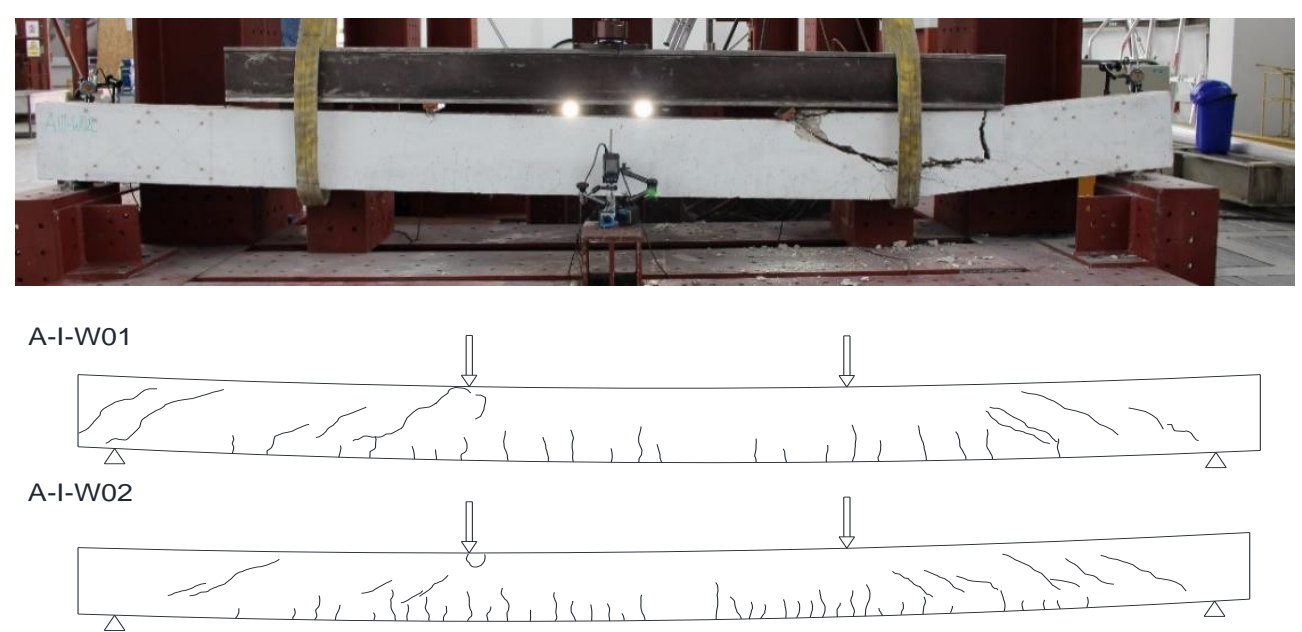

Fig. 3. Failure mode of A-WO series of beams
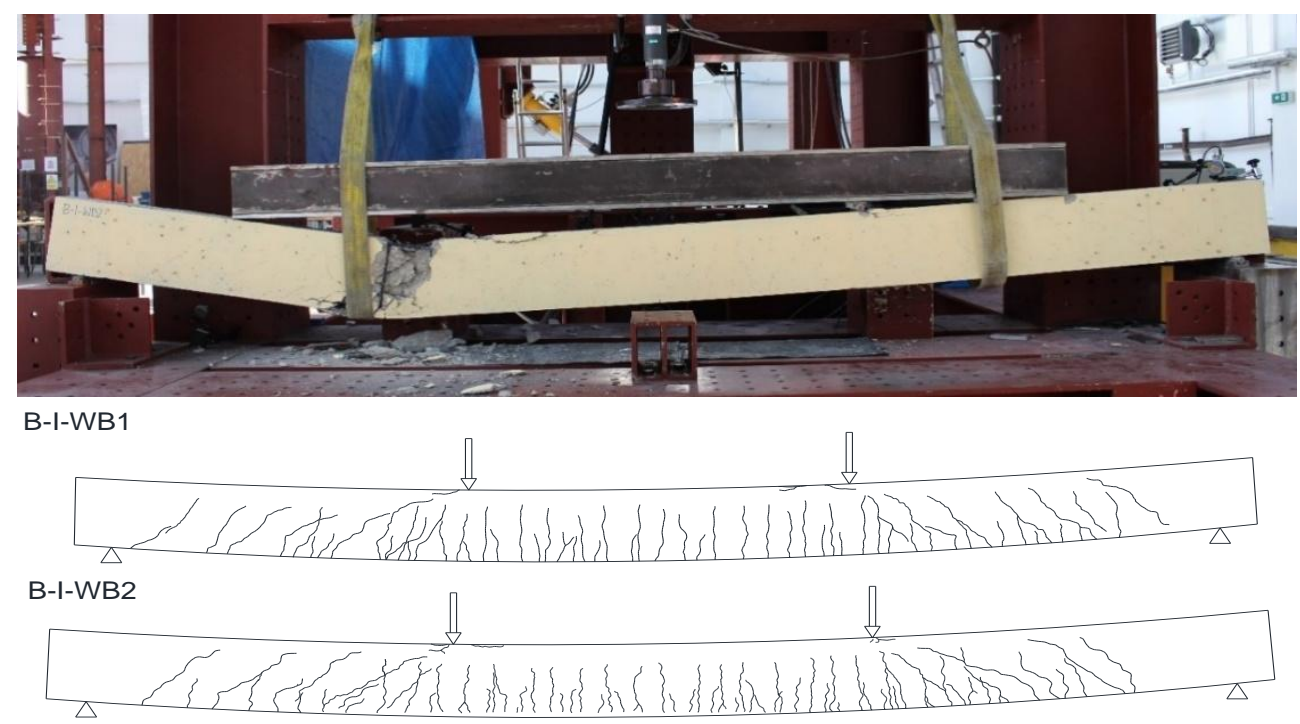

Fig. 4. Failure mode of B-WB series of beams

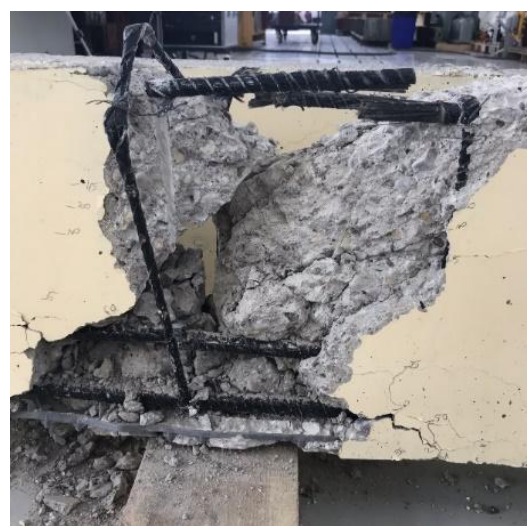

Fig. 5. Detail of destruction of beam with BFRP reinforcement

The ultimate forces $P_{\text {ult }}$ recorded for individual beams are presented in Table 3 together with the average value of the destructive force. The decrease in the mean value of ultimate force of the BFRP beam in comparison to the RC beam was $23 \%$. When analyzing the results of the bearing capacity assessment, it should be taken into account that bars with a smaller diameter were used in the BFRP beams. The 
difference in the diameter of steel and basalt bars significantly influenced the bearing capacity of the beams.

Table 3

Ultimate loads $P_{\text {ult }}$ for particular

\begin{tabular}{|c|c|c|c|c|c|c|c|c|}
\hline \multirow[t]{2}{*}{ SERIES } & $P_{u l t}$ & $\overline{P_{u l t}}$ & \multirow{2}{*}{$\begin{array}{l}\text { FAILURE } \\
\text { MODE }\end{array}$} & \multirow[t]{2}{*}{ SERIA } & \multirow[t]{2}{*}{$P_{\text {ult }}$} & $\overline{\boldsymbol{P}_{\text {ult }}}$ & $\Delta \boldsymbol{P}_{u l t}$ & \multirow{2}{*}{$\begin{array}{l}\text { FAILURE } \\
\text { MODE }\end{array}$} \\
\hline & $\mathrm{kN}$ & $\mathrm{kN}$ & & & & $\mathrm{kN}$ & $\%$ & \\
\hline \multirow{3}{*}{ A-W0 } & 137 & \multirow{3}{*}{126} & $\mathrm{~F}$ & \multirow{3}{*}{ B-WB } & 84 & \multirow{3}{*}{97} & \multirow{3}{*}{-23} & $F$ \\
\hline & 115 & & $\mathrm{~F}$ & & 110 & & & $\mathrm{~F}$ \\
\hline & 85 & & $S$ & & 55 & & & $S$ \\
\hline
\end{tabular}

$\mathrm{F}$ - failure due to flexural tension, $\mathrm{S}$ - failure due to shear

Fig. 6 shows the average deflection in the center of the span a [mm] depending on the load $P[\mathrm{kN}]$. The graphs depict extemporary deflections taking into account settlement of supports.

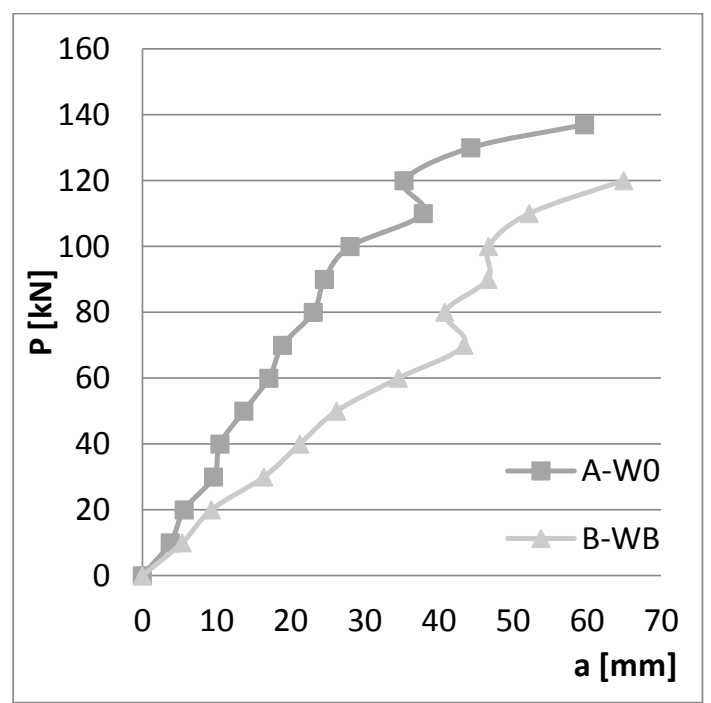

Fig. 6. Load P [kN] - deflection a [mm] curves

It was found that during the initial phase of load the BFRP beams already obtained a $40 \%$ increase in the deflection value in relation to the reference $\mathrm{RC}$ beams. With the increase in load, the difference in the value of deflection increased. Finally, the deflections of the reference beams were even twice smaller compared to the BFRP beams.

Fig. 7 shows the image of strain fields in concrete and crack pattern recorded for the A-WO and B-WB series beams obtained using the two-dimensional Digital Image Correlation method.

Fig. $7 \mathrm{a}$ and $7 \mathrm{~b}$ show the horizontal deformations in the middle part of the beams for an ultimate load. The change of color on the map reflects the appearance of cracks with different width. In the failure phase, the crack pattern of the beams in the middle part consisted of perpendicular cracks defining the destruction of the elements. RC beams were characterized by a fewer cracks with a smaller width. 
a)
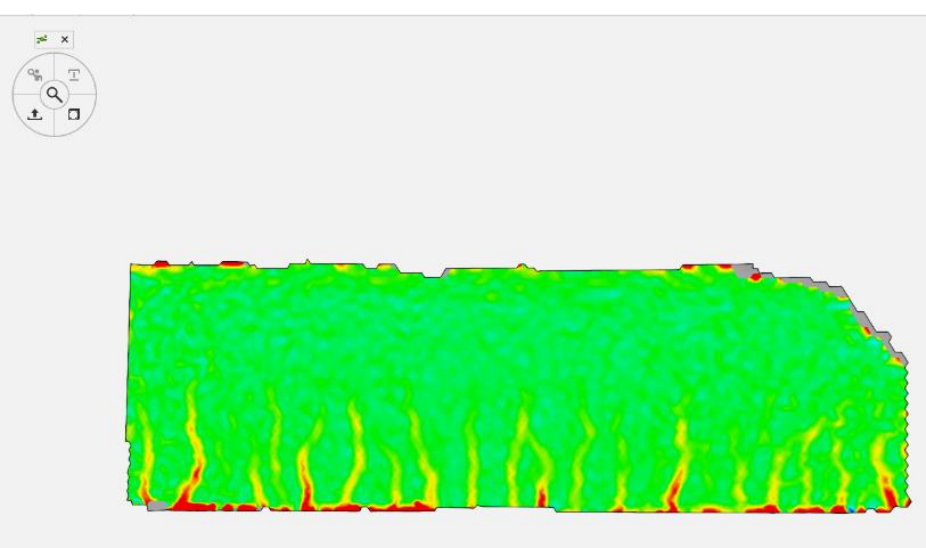

)

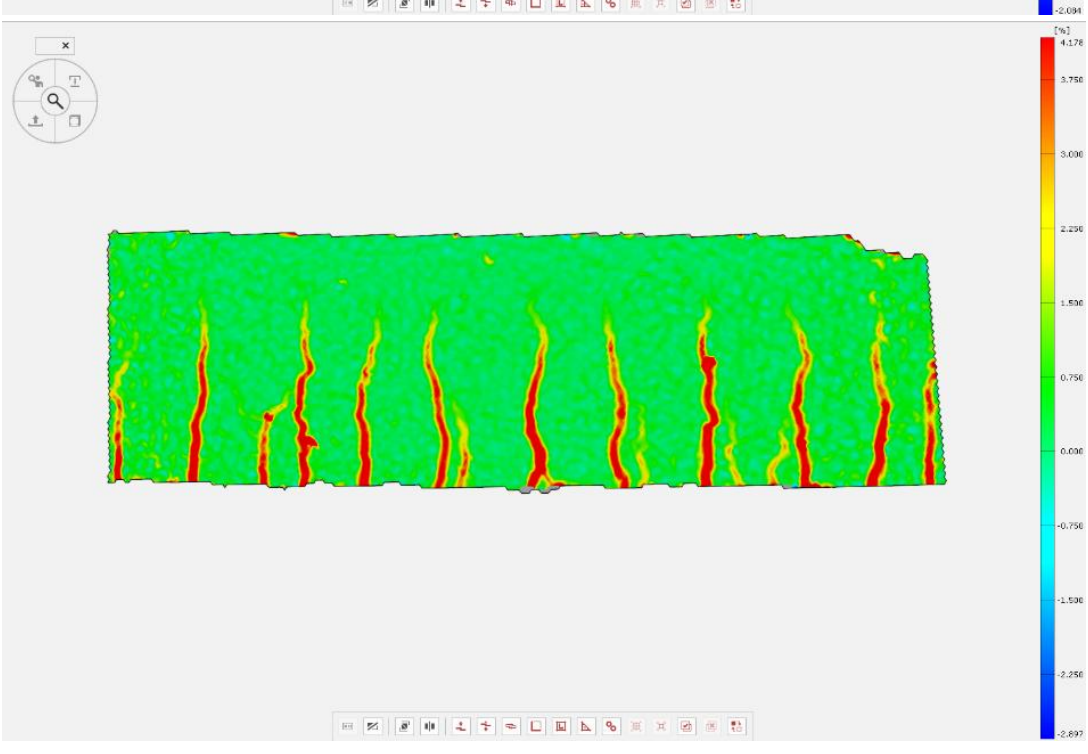

b)

Fig. 7. Image of strain fields in concrete and crack pattern a) A-WO b) B-WB

BFRP beams were characterized by greater deformations and a much larger number of wider cracks. The range of the cracks in the A-W0 series beams reached up to $1 / 3$ of the cross-section depth, whereas in the B-WB series beams the cracks reached a range up to $2 / 3$ of the cross-section depth. The lower stiffness of BFRP beams results from the smaller diameter and smaller value of modulus of elasticity of basalt bars compared to steel ones.

\section{CONCLUSION}

The bending or shearing capacity, deflections and crack pattern of BFRP beams and $\mathrm{RC}$ beams were tested. The emphasis was put on the evaluation of the failure character of concrete members with non-metallic reinforcement. Despite the smaller diameter of the reinforcing bars used, the BFRP beams achieved a satisfactory bearing capacity. The failure mode of both types of RC and BFRP beams was similar. However, the cracks in BFRP beams appeared at smaller value of load and their number during the destruction phase was significant. Due to the corrosion resistance of BFRP bars, the crack widths are not as important as in steel reinforced concrete structures. Significantly higher values of deformation are also allowed. In the final 
phase of loading in BFRP beams there was no local loss of adhesion between the bars and concrete, as in the case of steel bars. The failure of the beams occurred as a result of brittle fracture of the BFRP bars. The result of tests and analyses indicate the possibility of wide use of corrosion-resistant basalt reinforcement as an alternative to steel reinforcement in engineering structures. However, it is necessary to consider increasing the reinforcement ratio for BFRP beams, so that the stiffness of the structure is similar to that of $\mathrm{RC}$ beams. This will prevent excessive cracking and deformations. The test results can be used to refine the design guidelines for structural elements with BFRP reinforcement.

\section{ACKNOWLEDGEMENTS}

This research work was financially supported by Ministry of Science and Higher Education, Poland; project number MB/WBilŚ/6/2018.

\section{REFERENCES}

Atutis, M., Valivonis, J., Atutis, E., 2018. Experimental study of concrete beams prestressed with basalt fiber reinforced polymers. Part I: Flexural behavior and serviceability, Composite Structures, 183, 114-123.

Borhan, T.M., 2012. Properties of glass concrete reinforced with short basalt fibre. Mater Des, 42, 265-271.

Branston, J., Das, S., Kenno, S., Taylor, C., 2016. Mechanical behaviour of basalt fibre reinforced concrete. Construction and Building Materials, 24, 878-886.

Duic, J., Kenno, S., Das, S., 2018. Performance of concrete beams reinforced with basalt fibre composite Rebar. Construction and Building Materials, 176, 470-481.

Elgabbas, F., Vincent, P., Ahmed, E.A., Benmokrane, B., 2016. Experimental testing of basalt-fiber-reinforced polymer bars in concrete beams. Composites Part B, 91, $205 \mathrm{e} 218$.

Fiore, V., Scalici, T., Di Bella, G., Valenza, A., 2015. A review on basalt fibre and its composites. Composites Part B, 74, 74-94.

Kosior-Kazberuk, M., Wasilczyk, R., 2017. Analysis of deflection and cracking of concrete beams with non-metallic reinforcement. Budownictwo i Inżynieria Środowiska, 8, 173-183.

Lapko, A., Urbański, M., 2015. Experimental and theoretical analysis of deflections of concrete beams reinforced with basalt rebar. Archives of Civil and Mechanical Engineering, 15, 223-230.

EN 1992-1-1, 2008. Eurocode 2: Design of concrete structures - Part 1-1: General rules and rules for buildings. EUROPEA COMMITIEE FOR STANDARDIZATION.

Zhang, S, Shan, W., 2014. Prospect analysis of the application of BFRP bar to bridges. Key Eng Mater, 574, 21-29.

Zhu H, Wua G, Zhang L, Zhang J, Hui D. 2014. Experimental study on the fire resistance of $R C$ beams strengthened with near-surface-mounted high-Tg BFRP bars. Compos Part B, 60, 680-687. 